\title{
Endoluminal negative pressure wound treatment of anastomotic leakage in rectal surgery patients - critical review of the literature
}

\author{
Edward Hulo, M.D., $P h D$, Daniela Karasová, $M S, P h D$
}

\begin{abstract}
During past 20 years, the use of negative pressure wound therapy (NPWT) has shown its effectiveness and efficiency in treatment of various indications. These indications include treatment of septic complications of open surgery (open abdomen, entero-atmospheric fistulas, wound dehiscence including poststernotomy infections, staged abdominal wall repair, diabetic foot syndrome, and salvage of infected prosthetic material) or their prevention (prevention of complications in skin graft application and prevention of prosthetic graft infection).

New approaches and ways of application are evolving. One of the new therapeutic methods is endoluminal use in both upper and lower gastrointestinal tract. Authors performed and present thorough review of the literature on the use of endoluminal NPWT in anastomotic leakage in rectal surgery patients.

Authors conclude that "endo-NPWT" (NPWT used in the lumen of the gastrointestinal tract) is becoming a new and effective therapeutic method in the treatment of septic complications of patients after rectal surgery.
\end{abstract}

Keywords—anastomotic leakage, NPWT, VAC, wound healing, endo-NPWT

\section{INTRODUCTION}

$\mathbf{S}$ INCE its introduction, negative pressure wound therapy (NPWT) has shown its effectiveness and efficiency in a number of different indications. These indications include treatment of septic complications of open surgery (including open abdomen and management of entero-atmospheric fistulas, ${ }^{1}$ wound dehiscence including sternotomy infections, ${ }^{2]}$ different possibilities of staged abdominal wall repair, $\sqrt[3]{4}$ diabetic foot syndrome ${ }^{\left[\frac{5}{5}\right.}$ and salvage of infected prosthetic material ${ }^{6}$ or their prevention (prevention of complications in skin graft application ${ }^{7}$ and prevention of prosthetic graft infection ${ }^{8}$ ). Such uses consist of either external application - directly in the wound or intracorporal applications (intra-abdominal NPWT, intra-thoracic NPWT).

New approaches and ways of application of NPWT are evolving. One of the newest therapeutic methods is endoluminal use of NPWT in the lumen of both upper and lower gastrointestinal tract. This method was first described in $2006^{9}$ even though the first patients were treated as early as in $20011^{10}$ Indication for such use is dehiscence and leakage of an anastomosis in the gastrointestinal tract without signs of peritonitis. The rationale of such therapy is infection source

Manuscript received 11.2014; revised 03.2015.

Author affiliations: Clinic of Surgery and Transplantation Center, Jessenius faculty of Medicine, University Hospital Martin, Martin, Slovakia, (HE, KD) *Correspondence to: Edward Hulo (e-mail: edward1@ post.cz). control and filling of the abscess cavity with granulation tissue with subsequent over-epithelization. Benefit of such procedure is no need for reoperation with disconnection and salvage stoma creation (Torek operation in esophageal surgery, Hartmann operation in rectal surgery). The initial literature on endoluminal use of NPWT suggests positive results but its value and its role in the treatment of patients with anastomotic leakages has to be evaluated.

We performed a thorough review of the literature on the use of endoluminal NPWT in patients with anastomotic leakage in rectal surgery in attempt to describe its current indications and possible uses.

\section{Methods}

Authors performed a literature search through Web of Knowledge (Thomson Reuters) including Web of Science $\mathbb{R}$ (Science Citation Index Expanded (SCI-E), Social Science Citation index (SSCI), Conference Proceedings Citation Index - Science (CPCI-S), Conference Proceedings Citation Index - Social Sciences \& Humanities (CPCI-SSH), Book Citation Index - Science (BKCI-S), Book Citation Index - Social Sciences \& Humanities (BKCI-SSH), BIOSIS Citation IndexSM, Current Contents Connect $\AA$, MEDLINE $\AA$, Journal Citation

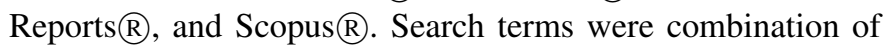
phrases: "VAC", "NPWT", "negative pressure wound therapy", "vacuum assisted closure", "endoluminal VAC", and "endoluminal NPWT".

All results were processed with search for articles, where endoluminal negative pressure was used for treatment of anastomotic leakage after rectal surgery and included a group of patients. These articles were further analyzed in terms of indication, type or construction of NPWT, level of negative pressure used, number of redresses done, length of treatment, stoma creation, and outcome of treatment in terms of morbidity and mortality.

\section{RESULTS}

After performing literature search we identified 12 articles, where endoluminal negative pressure was used for treatment of anastomotic leakage after rectal surgery ${ }^{9+20}$ These papers are summarized in table 【 


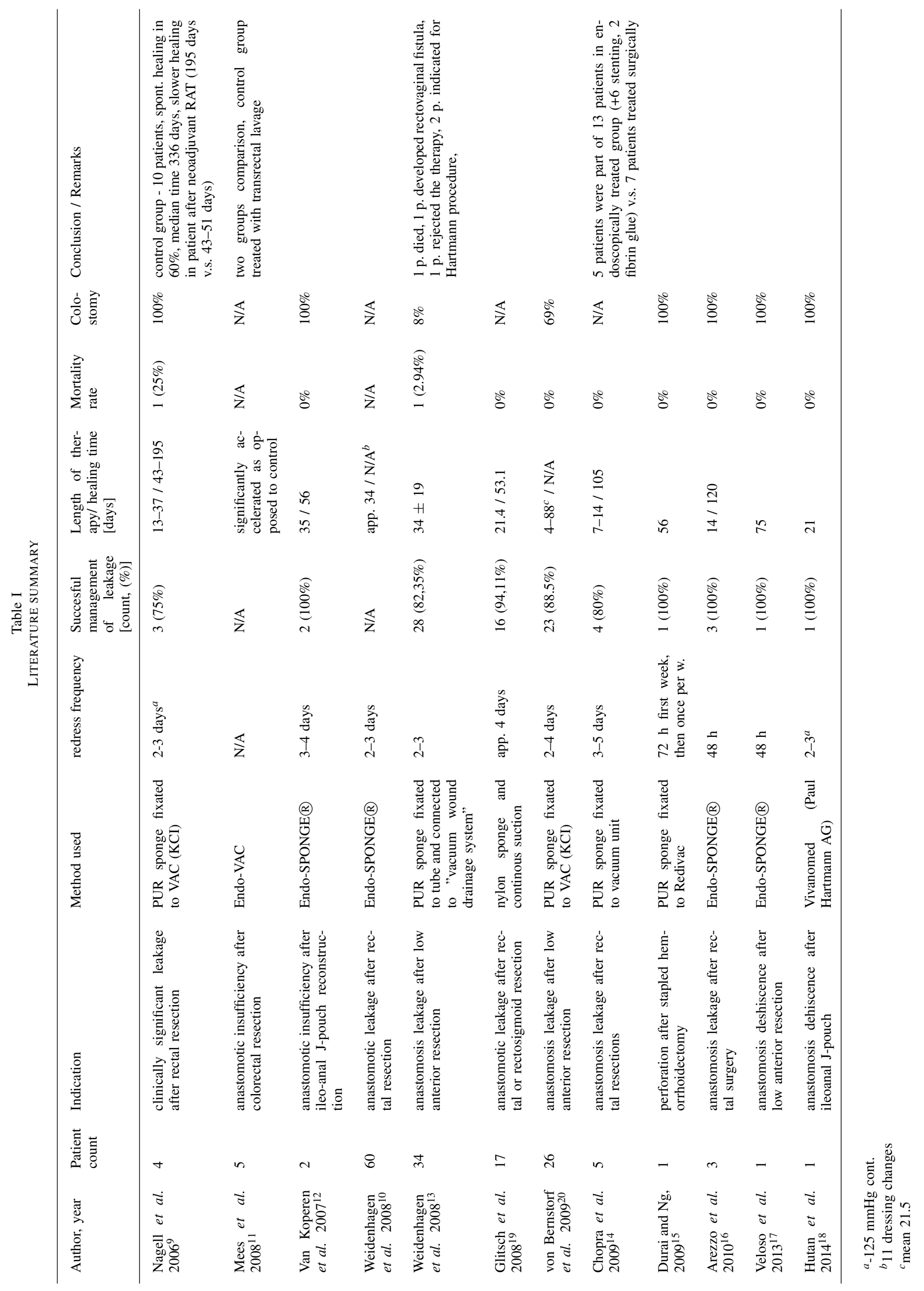


The number of treated patients in all but two papers are low (1-5 patients) in exception for two papers by Weidenhagen et al. both published in 2008, where 60, respectively 34 patients are described 10.13 It is not clear from the papers, if the patients described are not repetitively presented (one group is described as treated from 2001 till 2008, second is from 2002 to 2004). Anyhow, no more than 159 patients are presented in the literature as being treated with such method.

Anastomotic leakage after low anterior resection was reported as the main indication for treatment with endo-NPWTJ. In minority authors also recommended it in anastomotic leakage of ileoanal "J-pouch" anastomosis or perforation after stapled hemorrhoidectomy.

Currently, the only industrially made available unit is EndoSPONGE (Braun Medical, Braun Melsungen AG, Germany). This unit does not however allow to regulate negative pressure as well as lacks automatic signalization of vacuum loss and vacuum recreation. Because of this, different improvised techniques have been developed. They consist of a pyramid or oval shaped polyurethane foam (black foam) in conjunction with most commonly used NPWT units - either with VAC ${ }^{9}$ (KCI, San Antonio, TX, USA) or Vivand ${ }^{18}$ (Paul Hartmann AG, Heidenheim, Germany). Black foam is sutured to the tubing and then used with continuous negative pressure as in intra-abdominal NPWT.

Treatment technique starts with irrigation of an abscess cavity with possibility of endoscopic debridement. ${ }^{14}$ With the help of anoscope or endoscope, the foam is placed inside the cavity. Some authors proclaim, that foam should not be in contact with the mucosa, others describe intracolonic placement of NPWT 18 Redresses are done every 2-4 days until abscess cavity is shallow or fistula has regressed. This may take as long as 8 weeks. Some authors describe, that redresses in the later period may be done in ambulatory setting. 13

Success rate of leakage control is as high as $75-100 \%$ as opposed to $60 \%$ in patients with transrectal lavage and debridement, 9 or $50 \%$ in conservatively treated animal model. 21

Mortality rate in all patient groups is very low ( 2 patients) and independent from the medical condition treated (one intracerebral hemorrhage and one craniocerebral trauma after a fall from the bed).

Concerning stoma creation, most of the patients had it done either during the primary operation or during endo-NPWT, where it might complicate treatment with fecal impaction. Stoma reversal after healing is possible in most patients $(88$ $\% \frac{14}{14}$.

\section{DISCUSSION}

Anastomotic leakage is the most important complication of anterior rectal resection and rectal resection surgery and is the main cause for the high level of patient mortality and morbidity 22 It can lead to generalized peritonitis, with a severe septic progression involving multiple organ failure and potentially resulting in the death of the patient.

Clinically manifesting anastomotic leakages occur in approx. $15 \%$ of patients following rectal resection. ${ }^{23}$ The frequency depends on various patient characteristics, the height of the anastomosis, technique of anastomosis creation, and the prior treatment in the case of carcinomas.

The possibilities and therapeutic principles concerning anastomotic leakage remain the subject of controversial discussion to this day. The spectrum of possible treatments ranges from conservative measures such as broad antibiotic coverage, through drainage and an endoscopic irrigation up to surgical revision with stoma placement, a Hartmann operation or, finally, abdominoperineal extirpation. Potential drawback of surgical relaparotomy and stoma creation is the general morbidity of diverting stomas of up to $30 \%$ and the reduced reversal rate of under $50 \%$ in anastomotic leakage. 24 The particular procedure varies according to the point in time, the extent and localization of the anastomotic leakage, as well as the efficiency of the secretion drainage and the clinical condition of the patient. No controlled studies yet exist on the various different methods for treating anastomotic leakages.

Recently, the introduction of NPWT and its endoluminal use in the treatment of such defects showed promising results not only in experimental setting, ${ }^{21}$ but also in clinical one.

Rationale of treatment is reduction of septic burden by local debridement and negative pressure, evacuation of inflammatory cytokines and metabolites, promotion of granulation tissue and enhanced tissue perfusion. All these aspects cause the defect to decrease in size and after being shallow or small, it can be left for spontaneous closure.

Nagell et al. ${ }^{9}$ used this technique in four patients with anastomotic leakage after rectal surgery, using PUR foam in conjunction with KCI unit (KCI, San Antonio, Texas, USA). As compared to control group of ten patients treated conservatively, the successful management was higher by $15 \%$. Markedly higher was rate of healing, where patients in control group healed approximately in twice the time, as patients in treated group. Interesting information is that the healing rate of patients after neoadjuvant radiotherapy is markedly higher than those, who did not undergo this treatment (195 days vs. 4351 days). Mees et al .11 $^{11}$ also compared two groups of patients, where control group was treated with transrectal lavage. The rate of healing was significantly higher in patients treated with endo-NPWT.

Van Koperen et al. ${ }^{[12}$ used the method in the treatment of anastomotic leakage of ileoanal J-pouch anastomosis, using EndoSPONGE. Both presented patients were successfully managed with this technique and recovered in 8 weeks.

Weidenhagen et al $\|^{10}$ published two papers with a large group of patients with anastomotic leakage after rectal surgery. They presented successful management of over $80 \%$ of patients with a mean time of treatment being just over one month. The work, that is presented in both papers, in collaboration with "BBraun Melsungen AG, Germany" led to the development of EndoSPONGE technique and inventory. Arezzo $^{16}$ and Veloso $\sqrt{17}$ both show efficacy of EndoSPONGE treatment of patients with anastomosis leakage after lower anterior colon resection. In both papers, all patients were successfully managed with this technique.

Chopra et al. ${ }^{14}$ compared endoscopically treated group as opposed to surgically treated patients. The resolution rate of leakage was $77 \%$. Durai et al ${ }^{[15}$ showed an interesting 
case, where perforation was a complication of stapled hemorrhoidectomy. Authors used combination of VAC and Redivac for successful management of this complication. Hutan et al. 18 showed interesting case of anastomosis dehiscence of ileoanal J-pouch. Patient was treated with improvised Vivano system (Paul Hartmann AG, Heidenheim, Germany).

Although challenging, time and energy consuming (because of high frequency of redresses in the operation theater setting), this method gives the surgeon another powerful tool in local management of septic complication of reconstruction surgery in the rectal and anal area.

\section{CONCLUSION}

Endo-NPWT is becoming a new and powerful tool for the local management of septic complications, following rectal surgery. The data show higher rate of treatment with a higher success rate. For further and wider application and development of this method, more patients have to be treated and analyzed, but based on literature studies, the preliminary results are very promising and this method should be considered as an option in patients with indications.

\section{REFERENCES}

[1] J. M. Hutan, M. S. Hutan, J. Skultety, J. Sekac, P. Koudelka, A. Prochotsky, A. Yaghi, and P. Labas, "Use of intraabdominal VAC (vacuum assisted closure) lowers mortality and morbidity in patients with open abdomen," BLL, vol. 114, no. 08, pp. 451-454 2013. http://dx.doi.org/10.4149/BLL_2013 094

[2] M. Simek, R. Hajek, and I. Fluger, "Superiority of topical negative pressure over closed irrigation therapy of deep sternal wound infection in cardiac surgery," J Cardiovasc Surg, vol. 53, no. 1, pp. 113-20 2012.

[3] M. Hutan, "Sandwich mesh abdominal closure," Bratislavske lekarske listy, vol. 111, p. 461-4632010.

[4] M. Hutan, C. Bartko, I. Majesky, A. Prochotsky, J. Sekac, and J. Skultety, "Reconstruction option of abdominal wounds with large tissue defects," BMC Surgery, vol. 14, no. 1, p. 502014. http://dx.doi.org/10.1186/1471-2482-14-50

[5] M. Beno, J. Martin, and P. Sager, "Vacuum assisted closure in vascular surgery," Bratislavske lekarske listy, vol. 112, no. 5, pp. 249-52 2011.

[6] F. Berrevoet, A. Vanlander, M. Sainz-Barriga, X. Rogiers, and R. Troisi, "Infected large pore meshes may be salvaged by topical negative pressure therapy," Hernia, vol. 17, no. 1, pp. 67-73 2012. http://dx.doi.org/10.1007/s10029-012-0969-3

[7] C. Zhang, D. Liu, Z. Liang, F. Liu, H. Lin, and Z. Guo, "Repair of refractory wounds through grafting of artificial dermis and autologous epidermis aided by vacuum-assisted closure," Aesthetic Plastic Surgery, vol. 38, no. 4, pp. 727-732 2014. http://dx.doi.org/10. 1007/s00266-014-0341-3

[8] J.-F. Gillion and J.-P. Palot, "Abdominal wall incisional hernias: Infected prosthesis: treatment and prevention," Journal of Visceral Surgery, vol. 149, no. 5, pp. e20-e31 2012. http://dx.doi.org/10.1016/j. jviscsurg.2012.04.003

[9] C. F. Nagell and K. Holte, "Treatment of anastomotic leakage after rectal resection with transrectal vacuum-assisted drainage (VAC)," International Journal of Colorectal Disease, vol. 21, no. 7, pp. 657-660 2006. http://dx.doi.org/10.1007/s00384-005-0083-4

[10] R. Weidenhagen, K. Gruetzner, T. Wiecken, F. Spelsberg, and K. Jauch, "Endoluminal vacuum therapy for the treatment of anastomotic leakage after anterior rectal resection," Rozhl Chir, vol. 87, no. 8, pp. 397-402 2008.

[11] S. T. Mees, D. Palmes, R. Mennigen, N. Senninger, J. Haier, and M. Bruewer, "Endo-vacuum assisted closure treatment for rectal anastomotic insufficiency," Diseases of the Colon \& Rectum, vol. 51, no. 4, pp. 404-410 2008. http://dx.doi.org/10.1007/s10350-007-9141-z

[12] P. Van Koperen, M. Van Berge Henegouwen, J. Slors, and W. Bemelman, "Endo-sponge treatment of anastomotic leakage after ileo-anal pouch anastomosis: report of two cases," Colorectal Disease, vol. 10, no. 9, pp. 943-4 2008 .
[13] R. Weidenhagen, K. U. Gruetzner, T. Wiecken, F. Spelsberg, and K.-W. Jauch, "Endoscopic vacuum-assisted closure of anastomotic leakage following anterior resection of the rectum: a new method," Surg Endosc, vol. 22, no. 8, pp. 1818-1825 2007. http://dx.doi.org/10.1007/ s00464-007-9706-x

[14] S. S. Chopra, K. Mrak, and M. Hünerbein, "The effect of endoscopic treatment on healing of anastomotic leaks after anterior resection of rectal cancer," Surgery, vol. 145, no. 2, pp. 182-188 2009. http://dx.doi.org/10.1016/j.surg.2008.09.012

[15] R. Durai and P. C. H. Ng, "Perirectal abscess following procedure for prolapsed haemorrhoids successfully managed with a combination of VAC sponge and redivac systems," Tech Coloproctol, vol. 13, no. 4, pp. 307-309 2009. http://dx.doi.org/10.1007/s10151-009-0503-5

[16] A. Arezzo, A. Miegge, A. Garbarini, and M. Morino, "Endoluminal vacuum therapy for anastomotic leaks after rectal surgery," Tech Coloproctol, vol. 14, no. 3, pp. 279-281 2010. http://dx.doi.org/10. 1007/s10151-010-0569-0

[17] N. Veloso, J. D. Silva, M. Carvalho, I. Rosa, I. Medeiros, L. Gonçalves, R. Godinho, and C. Viveiros, "Endo-SPONGEß treatment for anastomotic leakage after colorectal surgery," GE Jornal Português de Gastrenterologia, vol. 20, no. 3, pp. 132-135 2013. http://dx.doi.org/10.1016/j.jpg.2012.08.002

[18] M. Hutan, C. Bartko, and A. Prochotský, "Endoluminálna podtlaková liečba (endonpwt) dehiscencie anastomózy ileoanálneho j-pouchu. endoluminal negative pressure wound therapy (endonpwt) of dehiscence of anastomosis of ileoanal j pouch," Slov chir, vol. 11, no. 2, pp. 72-73 2014.

[19] A. Glitsch, W. von Bernstorff, U. Seltrecht, I. Partecke, H. Paul, and C. Heidecke, "Endoscopic transanal vacuum-assisted rectal drainage (ETVARD): an optimized therapy for major leaks from extraperitoneal rectal anastomoses," Endoscopy, vol. 40, no. 3, pp. 192-199 2008. http://dx.doi.org/10.1055/s-2007-995384

[20] W. von Bernstorff, A. Glitsch, A. Schreiber, L. I. Partecke, and C. D. Heidecke, "ETVARD (endoscopic transanal vacuum-assisted rectal drainage) leads to complete but delayed closure of extraperitoneal rectal anastomotic leakage cavities following neoadjuvant radiochemotherapy," International Journal of Colorectal Disease, vol. 24, no. 7, pp. 819-825 2009. http://dx.doi.org/10.1007/s00384-009-0673-7

[21] L. H. Rosenberger, A. Shada, L. A. Ritter, D. M. Mauro, M. J. Mentrikoski, S. H. Feldman, and D. E. Kleiner, "Delayed endoluminal vacuum therapy for rectal anastomotic leaks after rectal resection in a swine model: A new treatment option," Clinical And Translational Science, vol. 7, no. 2, pp. 121-126 2014. http://dx.doi.org/10.1111/cts.12140

[22] E. Hulo, L. Strelka, and R. Kyčina, "Leak kolorektálnej anastomózy. leak of colorectal anastomosis," Slov. chir., vol. 11, no. 2, pp. 69-71 2014.

[23] O. Hallböök and R. Sjödahl, "Anastomotic leakage and functional outcome after anterior resection of the rectum," British Journal of Surgery, vol. 83, no. 1, pp. 60-62 1996. http://dx.doi.org/10.1002/bjs. 1800830119

[24] A. A. Khan, J. M. D. Wheeler, C. Cunningham, B. George, M. Kettlewell, and N. J. M. Mortensen, "The management and outcome of anastomotic leaks in colorectal surgery," Colorect Dis, vol. 10, no. 6, pp. 587-592 2008. http://dx.doi.org/10.1111/j.1463-1318.2007.01417.x

[25] S. Willis and M. Stumpf, "Insuffizienzen nach eingriffen am unteren gastrointestinaltrakt," Der Chirurg, vol. 75, no. 11, pp. 1071-1078 2004. http://dx.doi.org/10.1007/s00104-004-0895-8

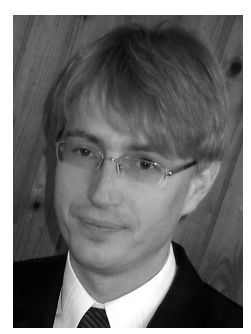

Dr. Edward Hulo, Ph.D. is the head of the septic department of Clinic of Surgery and Transplantation Center, University Hospital in Martin and an assistant professor at Jessenius Faculty of Medicine in Martin, Slovakia. He earned his Ph.D. degree in surgery at Comenius University in Bratislava with the topic: Monitoring of gene polymorphisms of the metabolic enzymes of glutathione S-transferase in patients with colorectal cancer. Dr. Hulo is especialy interested in laparoscopic colorectal surgery and treatment of chronic wounds and is a founding member and scientific secretary of the Slovak Society for Wound Healing. 